\title{
Endüstri 4.0’ın Lojistik Sektörüne Uygulanması: Lojistik 4.0
}

\author{
Abdurrahim Furkan Mercimek1 ${ }^{\text {(iD }}$ Tahsin Geçkil² (iD
}

\author{
${ }^{\mathbf{1} N e c m e t t i n ~ E r b a k a n ~ U ̈ n i v e r s i t e s i, ~ S o s y a l ~ B i l i m l e r ~ E n s t i t u ̈ s u ̈, ~ U l u s l a r a r a s ı ~ P a z a r l a m a ~ v e ~ L o j i s t i k ~ Y o ̈ n e t i m i, ~}$ \\ Konya, Türkiye, \\ afurkanmercimek@gmail.com (Corresponding Author/Sorumlu Yazar) \\ ${ }^{2}$ Necmettin Erbakan Üniversitesi, Uygulamalı Bilimler Fakültesi, Lojistik Yönetimi Bölümü, Konya, Türkiye
}

tahsingeckil@gmail.com

\begin{tabular}{|c|c|}
\hline Makale Bilgileri & ÖZ \\
\hline $\begin{array}{l}\text { Makale Geçmişi } \\
\text { Geliş: 13.11.2021 } \\
\text { Kabul: 16.12.2021 } \\
\text { Yayın: 29.12.2021 } \\
\text { Anahtar Kelimeler: } \\
\text { Dijitalizasyon, } \\
\text { Endüstri 4.0 } \\
\text { Lojistik 4.0 } \\
\text { Nesnelerin İnterneti } \\
\text { Dijital İkiz }\end{array}$ & 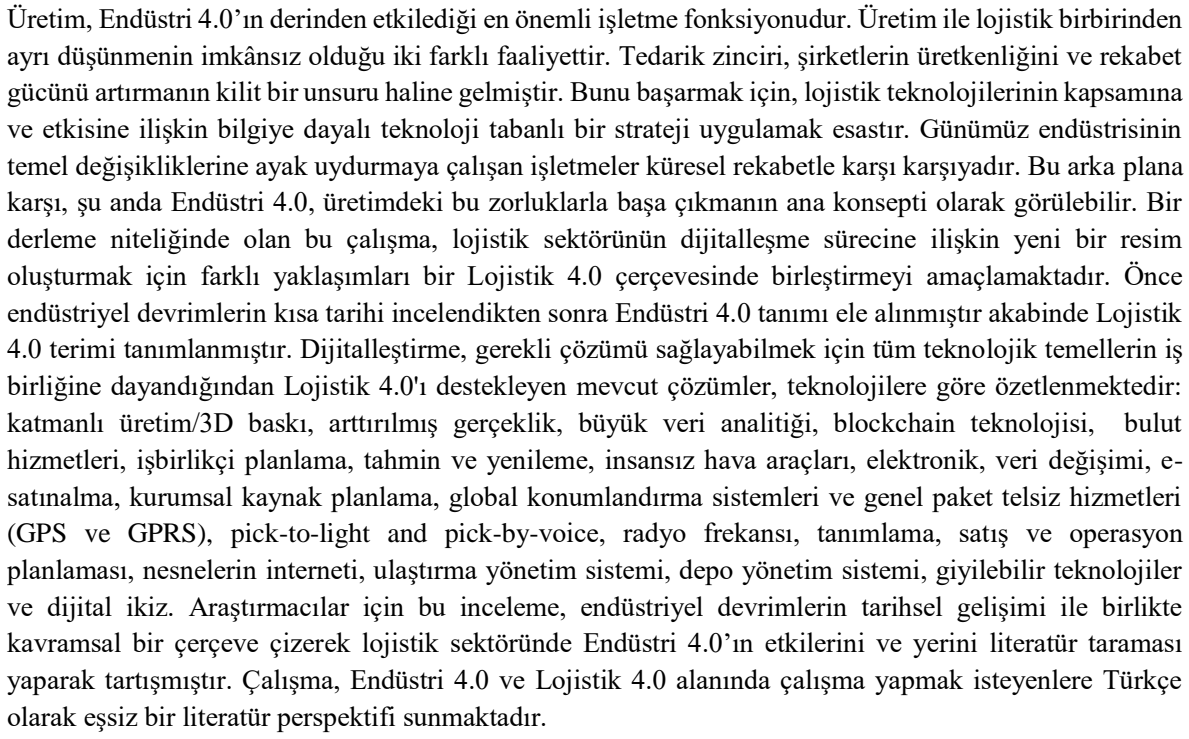 \\
\hline
\end{tabular}

The Application of Industry 4.0 on Logistics Sector: Logistics 4.0

\begin{tabular}{|c|c|}
\hline Article Info & ABSTRACT \\
\hline $\begin{array}{l}\text { Article History } \\
\text { Received: } 13.11 .2021 \\
\text { Accepted: 16.12.2021 } \\
\text { Published: } 31.12 .2021 \\
\text { Keywords: } \\
\text { Digitalisation } \\
\text { Industry 4.0 } \\
\text { Logistics 4.0 } \\
\text { Internet of Things } \\
\text { Digital Twins }\end{array}$ & $\begin{array}{l}\text { Industry } 4.0 \text { has a significant impact on production, which is the crucial business function. Production and } \\
\text { logistics are two distinct activities that cannot be separated from one another. The supply chain has become } \\
\text { a critical component of boosting a company's efficiency and competitiveness. To achieve this, a knowledge- } \\
\text { based, technology-based plan for the scope and effect of logistics technologies have to be implemented. } \\
\text { Businesses seeking to stay up with today's modern industry's fundamental developments confront worldwide } \\
\text { competition. In light of this, Industry } 4.0 \text { is presently regarded as the most important idea for overcoming } \\
\text { these production difficulties. This compilation research intends to integrate multiple methodologies in a } \\
\text { Logistics } 4.0 \text { framework to generate a fresh image of the logistics industry's digitization progress. First, a } \\
\text { brief history of industrial revolutions was explored, followed by a discussion of the notion of Industry } 4.0 \\
\text { and finally the term Logistics } 4.0 \text {. As digitalization relies on the collaboration of all technical bases to give } \\
\text { the desired answer, existing solutions supporting Logistics } 4.0 \text { are outlined by technologies: additive } \\
\text { manufacturing/3D printing, augmented reality, big data analytics, blockchain technology, cloud services, } \\
\text { collaborative planning forecasting and replenishment, drones, electronic data interchange, e-procurement, } \\
\text { enterprise resource planning, global positioning systems and general packet radio services (GPS and GPRS), } \\
\text { pick-to-light and pick-by-voice, radio frequency identification, sales and operations planning, internet of } \\
\text { things, transportation management system, warehouse management system, wearable technologies and digital } \\
\text { twin. For scholars, this paper drew a conceptual framework based on the historical development of industrial } \\
\text { revolutions and reviewed the literature to examine the impact and role of Industry } 4.0 \text { throughout the supply } \\
\text { chain management. For people interested in working in the subject of Industry } 4.0 \text { and Logistics } 4.0 \text {, the } \\
\text { research provides a unique literary viewpoint in Turkish. }\end{array}$ \\
\hline
\end{tabular}

Atıf/Citation: Mercimek A. F. \&.Geçkil, T. (2021). Endüstri 4.0'ın lojistik sektörüne uygulanması: Lojistik 4.0, Five Zero, 1(1), 57-77. 


\section{GİRIŞ}

Sanayi devrimi, dünya tarihinde insan türünün varoluş çerçevesini değiştiren ender olaylardan biri olmuştur. Büyüklük açısından karşılaştırılabilir önceki tek gelişme, hayatta kalmak için temel üretim biçimi olarak avcılık ve toplayıcılıktan tarıma geçiş olan Neolitik devrim olmuştur. Hem sanayi devrimi hem de Neolitik devrim, insanların nasıl çalıştıkları, nerede yaşadıkları konusunda köklü değişiklikler getirmiştir (Stearns, 2012). Neolitik devrimden günümüze doğru geldikçe, başlangıçta yalnızca ilkel ihtiyaçlar için gerekli icatlar üretilmiş olsa da değişimin hızı onun takibini imkânsız hale getirmiştir. Dijitalleşme, günlük hayatın birçok alanında önemli bir role sahip olmuştur. Dünyanın en popüler aktörlerinden biri olan teknoloji, sürekliliğini yitirmeyen bir öneme sahip olsa da endüstriler nezdinde hayati bir öneme sahiptir. Bu artan ilgi aynı zamanda küçük ve orta ölçekli işletmelerden büyük fabrikalara kadar birçok işletme nezdinde mevcut bir ihtiyacı karşılamak için bazı köklü değişikliklere de neden olmaktadır. Sanayi, insanların değişen ihtiyaçlarını karşılamak için dinamik kalması gereken bir alandır. Bu nedenle, her geçen gün üretimde kullanılan yöntemler değiştikçe, giderek daha fazla şirket de teknolojileri iş süreçlerine entegre etmek ve böylece süreçlerini dijitalleştirmek için gerekli adımları atmaktadır (Roth, 2016b). Endüstri 4.0, üretim ve hizmet sistemlerinin tüm aşamalarının dijitalleşme stratejisinde önemli bir rol oynamaktadır.

Endüstriyel açıdan bakıldığında, yeni icatların yardımıyla yüzyıllar boyunca önemli değişiklikler ortaya çıkmıştır. Kronolojik olarak birinci endüstri devrimi buhar gücü kullanılarak demir ve tekstil sanayilerinin verimliliğini artırmıştır. Birinci Dünya Savaşı'ndan hemen önce gerçekleşen ikinci endüstri devrimi elektrik gücünün sayesinde seri üretime geçişi simgelemektedir. Ekonomik manzarayı değiştiren üçüncü endüstri devriminde ise dijital devrim, elektroniklerin kullanımı ve bilgi teknolojilerinin gelişmesiyle üretimi daha da seri hale getirmiştir. Endüstri 1.0'a gelmemiz 4 bin 300 yıl alırken, 2.0'a geçmemiz 70 yılımızı aldı. 3.0'a ise 45 yılda geçtik ve şimdi günümüzde Endüstri 4.0'a ulaştık. Kavram olarak Endüstri 4.0 bu tarihsel süreçte değerlendirilirse değişimi ne derece hızlı yönetmemiz gerektiği gerçeğiyle yüzleşmemiz kolaylaşacaktır. Çevremiz mekân, insan ve zaman adı verilen üç olgu ile şekilleniyor. Daha önce zaman kısıtlamasından seri üretimle kurtulduktan sonra dijitalleşme, bu olgulardan mekânın yok edilmesini amaçlamaktadır ve bu çok hızlı gerçekleşmektedir (Küntay ve ark., 2017). Bu nedenle dördüncü sanayi devrimi yeni bir çığır açmaktadır.

Endüstri 4.0, 2011 y1lında bilgisayarlı üretimi teşvik eden bir Alman hükümet projesinden ortaya çıkan bir terimdir. 18. yüzyılda gerçekleşen sanayi devriminden bu yana "dördüncü sanayi devrimi” olarak da anılmaktadır. Dördüncü sanayi devrimi, Alman Ekonomik Kalkınma Ajans1 tarafından 2011 yılında ortaya atılmasından sonra üçüncüsü üzerine kurulmuştur. Endüstri 4.0 terimi, katmanlı üretim/3D baskı, arttırılmış gerçeklik, büyük veri analitiği, blockchain teknolojisi, bulut hizmetleri, işbirlikçi planlama, tahmin ve yenileme, insansız hava araçları, elektronik, veri değişimi, e-satınalma, kurumsal kaynak planlama, global konumlandırma sistemleri ve genel paket telsiz hizmetleri (GPS ve GPRS), pick-to-light and pick-by-voice, radyo frekansı, tanımlama, satış ve operasyon planlaması, nesnelerin interneti, ulaştırma yönetim sistemi, depo yönetim sistemi, giyilebilir teknolojiler ve dijital ikiz gibi çok sayıda fiziksel ve dijital teknolojinin bir araya gelmesiyle tanımlanmaktadır. Uluslararası olarak endüstriyel nesnelerin interneti olarak bilinen Endüstri 4.0, imalat endüstrisinin gelecekteki rekabet gücünü sağlayan akıllı, kendi kendini düzenleyen ve birbirine bağlı bir endüstriyel değer yaratmayı amaçlamaktadır (Kagermann ve ark., 2013).

Endüstri 4.0 terimi bir süredir var olmasına rağmen, hala tek tip bir tanım bulunmamaktadır (Siepmann, 2016b). Roth'un (2016b) bütüncül tanımı; Endüstri 4.0, değer zinciri boyunca müşteri 
kullanımını optimize etmek, akıllı ürün ve hizmetleri kullanmak için değer yaratma süreçlerini daha şeffaf ve verimli hale getirmek amacıyla tüm insan ve makine aktörlerinin ağ oluşturması ve ilgili tüm bilgilerin dijitalleştirilmesi ve gerçek zamanlı olarak değerlendirilmesi olarak tanımlanmaktadır.

Endüstri 4.0'ın sadece endüstriyel ortamı değil, hizmet ve lojistik dahil olmak üzere ilgili tüm sektörleri etkilemiştir ve değişimin devam etmesi beklenmektedir. Lojistik sektörü, endüstriyel süreçlerin tüm tedarik zincirinde önemli bir role sahiptir ve bu nedenle endüstriyel ortamda değişen ihtiyaçlar lojistik sektörünü doğrudan etkilemektedir. Bu noktadan hareketle bu çalışma, Endüstri 4.0'ın lojistik sektörü üzerindeki etkilerini ortaya koymayı amaçlamaktadır. Çalışmanın ilk bölümünde kullanılan metodolojinin tasvir edilmesinin akabinde literatür taraması yapılmış, kısaca Endüstri ve Lojistik 4.0 ile ilgili bazı genel terimler ve tanımlar tespit edilmeye çalışılmış ve COVID-19 salgını sonucu lojistik sektöründe faaliyet gösteren firmaların dijital eğilimleri üzerine bir araştırma yapılmıştır. Daha sonra kavramsal çerçeve ve tanım bölümünde ise Endüstri 4.0 ve Lojistik arasında ilişkinin daha iyi anlaşılabilmesi için endüstriyel devrimler kısaca incelenmiş ve Endüstri 4.0 tanımlanmıştır. Akabinde Lojistik 4.0 incelenerek aralarındaki ilişki kaleme alınmış ve Lojistik 4.0 yönetimi için ana teknolojiler değerlendirilmiştir.

\section{METODOLOJİ}

Bugün, Endüstri 4.0 konusu hâlâ gelişmekte olan ve oldukça çeşitli bir araştırma alanıdır. Keşifsel araştırma yöntemlerinin uygulanması uygun olan bir alandır. Literatürde keşifsel araştırma yürütmenin üç temel yolundan bahsedilmektedir (Saunders ve ark., 2009): Literatür araştırması, konuyla ilgili uzmanlarla görüşmek ve odak grup görüşmeleri yapmak. Lojistik ve endüstri 4.0 ilişkisini tanımlamak için kapsamlı bir bakış açısı oluşturmak için bütünleştirici bir literatür taraması yapılmıştır.

Konuya ve bu alandaki mevcut araştırmalara dayanarak, lojistik ve tedarik zinciri yönetiminde Endüstri 4.0 hakkında sistematik bir inceleme uygulandı. Bu makale için, incelemeler yapmak için önerilen beş adıma (Denyer ve Tranfield, 2009) dayalı olarak yapılandırılmış bir inceleme metodolojisi benimsenmiştir: (1) soru formülasyonu, (2) yer belirleme çalışmaları, (3) çalışma seçimi ve değerlendirmesi, (4) analiz ve sentez ve (5) sonuçların raporlanması ve kullanılmasıdır.

Soru formülasyonu aşamasında araştırma soruları; (1) Endüstri devrimlerinin tarihsel gelişim süreci nasıl olmuştur? (2) Endüstri 4.0 teriminin tanımı nedir? (3) Lojistik 4.0 teriminin tanımı nedir ve nasıl ortaya çıkmıştır? (4) Endüstri 4.0 lojistik sektörünü nasıl etkilemektedir ve modern tedarik zinciri için ana teknolojiler nelerdir?

\section{LITERATÜR TARAMASI}

Kamble ve ark. (2018) göre Endüstri 4.0, minimum kaynakla maksimum çıktıya erişmek için yeni teknolojilerin uyarlanmasıyla üretim sistemini değiştiren bir reformdur. Daha genel olarak, Endüstri 4.0, daha iyi iş sonuçlarının tahminini, planlanmasını ve kontrolünü sağlamak için karmaşık fiziksel makinelerin ve internet yazılımı/sensör cihazlarının entegrasyonu ile değer zinciri organizasyonları ve yönetimler için yeni bir adımdır.

Endüstri 4.0, resmî belgelerde gündeme gelmiştir ve bir sanayi devriminin habercisi olmuştur (MacDougall, 2014). Alman hükümeti 2011 yllında sanayiyi ulusal bir stratejik girişim olarak konumlandırmıştır. $\mathrm{Bu}$ girişimin temel amacı nesnelerin interneti, değer zinciri ve iş modelleri aracılığıyla dijital üretimi teşvik etmektir (Commission, 2017). 2011 yılından sonra bu kavram ve bakış açısı tüm dünyaya yayıldı ve 2016 yılı itibari ile Dünya Ekonomik Forumu'nun ana konu başlı̆ğ haline 
gelmiştir (Forum, 2016).

Ana fikri, firmaların makineleri, tedarik zinciri sistemi, üretim süreçleri ve müşterileri arasında gerçek zamanlı piyasa ve operasyonel bilgi sağlamak için dijitalleşme yoluyla iş yönetimi olarak özetlenebilir (Ardito ve ark., 2018). Hermann ve ark. (2015) tarafindan yapılan kapsamlı literatür taramasına göre Endüstri 4.0'ın dört temel unsuru; Siber-Fiziksel Sistemler, Nesnelerin İnterneti, Hizmetlerin İnterneti ve Akıllı Fabrika. Ayrıca Makineden Makineye iletişim, Akıllı Ürünler, Büyük Veri, Bulut Bilişim ve Veri Hizmetleri de bu unsurların alt bileşenleri olarak kabul edilmektedir (Hermann ve ark., 2015).

Literatürde Lojistik 4.0 terimine atıfta bulunulan çok az makale bulunmaktadır. Strandhagen ve ark. (2017) Lojistik 4.0'ı beş özelliğe göre tanımladı: örneğin optimize edilmiş yönlendirme için gerçek zamanlı büyük veri analitiği, yeni üretim teknikleri nedeniyle azaltılmış depolama gereksinimi, optimize edilmiş envanter kontrolüne yol açan izleme ve karar sistemlerine sahip otonom robotlar, gerçek anlamda bilgi alışverişi, zaman kaçınma örneğin kamçı etkileri ve akıllı öğeler nedeniyle bilgi kesintisi olmaz. Buna karşıllk Barreto, Amaral ve Pereira (2017), siber fizik sistemler tarafindan eklenen yenilikler ve uygulamalarla lojistik kullanımının birleşimine atıfta bulunmuştur. Ek olarak, Timm ve Lorig (2015) Lojistik 4.0'ı donanım odaklı lojistikten yazılım odaklı lojistiğe dönüşüm olarak tanımlamıștır.

Medyakova ve ark. (2020), dijital teknolojilerin ulaşım alanında pandemi öncesi ve pandemi sonrası süreçlerde kullanımını analiz etmeyi amaçlamıştır. Pandemi öncesi dönemde maliyet ve zaman kısıtlaması gibi nedenlerle dijital yeniliklerin kademeli olarak gerçek süreçlere dahil edildiğini belirtmişlerdir. Dünyanın en büyük ulaşım sistemlerinden birine sahip olan Rusya'da pandemi öncesi ve sonrası dijital teknolojilerin kullanımının analiz edildiği çalıșma, ulaşım sektöründe dijital teknolojilerin kullanımının ve dijital dönüşümün, salgın döneminin başlamasından sonra ivme kazandığını öne sürmektedir.

Queiroz ve ark. (2020), COVID-19 salgınının pandemi ve salgınların dünya çapında tedarik zincirlerine ciddi şekilde zarar verebileceğini ortaya koyduğunu savundukları çalışmalarında insani lojistiğin önemine değinmiştir. İnsani lojistik konusunda çok fazla çalışma olmasına rağmen ticari tedarik zincirlerinin salgın sırasında savunmasız kaldığını savunan yazarlar, literatür taraması yöntemini kullanarak ticari tedarik zincirlerinin pandemi ve salgın hastalıklar sırasında daha verimli çalışmasını sağlayacak bir model önerisi geliştirmeyi amaçlamışlardır. Çalışma sonucunda, salgın ve pandemi dönemlerinde tedarik zinciri yapısını adaptasyon, dijitalleşme, hazırlık, iyileştirme, dalgalanma etkisi ve sürdürülebilirlik olmak üzere altı aşamada yönetmenin daha verimli olacağı bir model oluşturmuşlardır. Çalışma ayrıca tedarik zinciri yönetimi literatüründe pandemi ile ilgili bilimsel çalışmaların yetersiz olduğunu vurguluyor. COVID-19 pandemi sürecinin tedarik zincirleri üzerindeki etkisini inceleyen bir başka çalışma Nandi ve ark. (2020) tarafından hazırlanmıştır. Pandemi sürecinde geleneksel tedarik zincirlerinin zayıf noktalarının tespit edilmesinin daha kolay olduğunu savunarak, bu süreci bir firsat olarak değerlendirmek ve tedarik zincirlerini daha dayanıklı, şeffaf ve sürdürülebilir kılmak için gerekli tedbirlerin alınması gerektiğini savunmaktadırlar.

\section{ENDÜSTRIYYEL DEVRIMLERIN TARİHSEL GELIŞSIMI}

Literatürde "sanayi devrimi" ve "sanayileşme" terimleri birbirinin yerine kullanılmaktadır. Tarih boyunca birçok sanayi devriminin ortaya çıkışı, türleri, doğası ve kavramlarıyla ilgili soruları gündeme getirmektedir (Coleman, 1956).

Sanayi Devrimi, sanayi öncesi toplumdan sanayi toplumuna geçiş sırasında, kişi başına düşen GSYİH'nın reel olarak sürekli ve önemli bir şekilde artması gibi modern ekonomik büyümenin yükselişini ifade etmektedir. Devrim süreci, doğası gereği ani ve hızlı değil, derin ve kapsamlıdır. Büyük 
Britanya ilk sanayi ülkesiydi ve geçişi 1750 'lerden 1850 'lere neredeyse bir asır sürmüştür. Ancak, kişi başına düşen reel gelir 1840'lardan sonra yılda yüzde birin üzerinde artmaya başladı. Birçok yeni sanayi sektörü, erken bir aşamada üretkenlikte önemli artışlara ulaşmıştı. Ancak kötü hasatlar, sık savaşlar, yüksek nüfus artışı ve ekonomik yapıdaki değişiklikler, özellikle öncü ülke olan İngiltere'de büyüme oranını olumsuz etkilemiştir. Daha sonra sanayileşen ülkeler, genel olarak daha hızlı bir gelişme hızına ve daha yüksek bir büyüme oranına sahip olmuştur (Vries, 2008).

Sanayi devrimi tek başına tarihsel bir olay olarak görülmese de son üç yüzyıl boyunca insanlık tarihindeki en önemli gelişmelerden birisi olarak literatüre geçmiştir (Stearns, 2012). Bu fenomen yaklaşık iki buçuk yüzyıl önce başlamıştır. Sanayi devrimi, mal üretmeye yönelik yeni yöntemlerle insanların nerede yaşadıklarını, nasıl çalıştıklarını, siyasi sorunları nasıl tanımladıklarını, hayata bakış açılarını ve daha fazlasını yeniden şekillendirmiştir. Aynı zamanda çağdaş dünyayı şekillendirmeye devam etmektedir. En eski sanayi ülkeleri kendilerini hâlâ onun etkisine adapte ederken, Çin gibi daha yeni sanayi toplumları, orijinal sürecin unsurlarını tekrarlıyor, ancak kapsamını yeni yönlere genişletiyor (Stearns, 2012).

Sanayileşme, 19. ve 20. yüzyıllarda başlayan ve 21. yüzyılı ve hayatımızı şekillendirmeye devam eden dünya tarihindeki değişiklikleri getiren en büyük güçtür. Sanayi devrimleri üç dalga halinde gerçekleşti. Birincisi, 1770'lerde Büyük Britanya'daki gelişmelerle başlayarak Batı Avrupa ve Amerika Birleşik Devletleri'nde meydana gelirken, ikinci dalga Rusya ve Japonya'yı, doğu ve güney Avrupa'nın bazı bölgelerini, ayrıca 1880'lerden itibaren Kanada ve Avustralya'yı etkilemiştir. En son dalga 1960'larda Pasifik Kıyılarında başladı ve yirmi yıl sonra Türkiye, Hindistan, Brezilya ve Latin Amerika'nın diğer bölgelerine ulaştı. Her büyük sanayileşme dalgası, doğrudan sanayileşmemiş ve temel sosyal ve ekonomik ilişkilerini dönüştüren diğer ülkeleri hızla etkisine almıştır (Stearns, 2012).

İlk üç sanayi devrimi yaklaşık 200 yıllık bir süreye yayılmıştır. 1700'lerin sonlarında buhar motoruyla çalışan mekanik tezgahlarla başlayan kumaş üretimi, özel evlerden merkezi fabrikalara taşınarak verimlilikte aşırı bir artışa neden olmuştur. Yaklaşık 100 yıl sonra Ohio, Cincinnati'deki mezbahalarda konveyör bantlarının kullanılarak yapılan üretim İkinci Sanayi Devrimi'nin başlangıç işaretidir. Sonraki yıllar, Ford T modelinin Amerika Birleşik Devletleri'nde üretilmesiyle bu dönemin doruk noktasını görülmüştür. Sürekli üretim hatlarının ve konveyör bantların devreye girmesi, seri üretimin avantajı nedeniyle üretkenlikte aşırı artışa yol açmıştır. Otomasyon sistemlerinin dijital programlanmasını sağlayan atılım, 1969 'da Modicon tarafından ilk programlanabilir mantık denetleyicisinin sunumuyla gelmiştir ve üçüncü Sanayi Devrimi'nin başlangıcı olarak kabul edilmiştir. Programlama paradigması, son derece esnek ve verimli otomasyon sistemlerine yol açan günümüzün modern otomasyon sistemi mühendisliğini hâlâ yönetmektedir (Drath ve Horch, 2014).

Dördüncü Sanayi Devrimi, Siber-Fiziksel Sistemler aracılığıyla ortaya çıkmıştır. Bu sistemler, fiziksel operasyonları bilgisayar ve iletişim altyapıları ile ağları ve siber dünyaya erişilebilirlikleri aracılı̆̆ıyla birbirine bağlayan endüstriyel otomasyon sistemleridir (Jazdi, 2014).

Fiziksel operasyonların endüstriyel üretim, bilgi ve iletişim teknolojilerine entegrasyonu Endüstri 4.0 olarak adlandırılmaktadır. Endüstri 4.0, son yıllarda akademisyenler tarafından daha fazla ilgi görmeye başlamıştır. Endüstri 4.0 terimi, tarihte üç sanayi devriminden sonraki sanayi devrimi için kullanılmaktadır. Birinci Sanayi Devrimi, 18. yüzyılın ikinci yarısında mekanik üretim tesislerinin devreye girmesiyle başlamış ve 19. yüzyılda hız kazanmıştır. Elektrifikasyon ve iş bölümü, 1870'lerden başlayarak İkinci Sanayi Devrimi'ni tetikledi. Gelişmiş elektronik ve bilgi teknolojisinin yardımıyla üretim sürecinin otomasyonundaki ilerleme, 1970'lerde Üçüncü Sanayi Devrimi'ni (dijital devrim) başlattı (Hermann ve ark., 2016). 


\section{ENDÜSTRİ 4.0: KAVRAMSAL ÇERÇEVE}

Dördüncü sanayi devriminin kökeni, milenyumun şafağında internetin ortaya çıkışına kadar uzanır (Sentryo, 2019). İlk üç sanayi devriminin başlangıç dönemi, yeni bir enerji türünün ortaya çıkmasıyla başlamıştır; ancak Dördüncü Sanayi Devrimi, yeni bir enerji türü doğurmaktan ziyade yeni bir teknolojik olgu olan dijitalleşmeyi başlatan ilk devrimdir (Sentryo, 2019).

Endüstri 4.0 kavramı 2011 yılında Henning Kagermann (Almanya'daki SAP yazılım şirketinin eski üst yöneticisi) tarafından ortaya atıldı (Paprocki, 2016). "Dördüncü Sanayi Devrimi" olarak anılan Endüstri 4.0, "akıllı üretim", "endüstriyel internet" veya "entegre endüstri” olarak da bilinmektedir (Hofmann ve Rüsch, 2017). Amac1, dijitalleşmeyi ve ürünlerin, değer zincirlerinin ve iş modellerinin birbirine bağlanmasını artırarak dijital üretimi ileriye taşımak olan Endüstri 4.0, Federal Eğitim ve Araştırma Bakanlığı ve Ekonomik İşler ve Enerji Bakanlığı aracılığıyla Alman hükümetinin ulusal stratejik girişimidir. Ayrıca araştırmayı, endüstri ortakları arasında ă̆ oluşturmayı ve standardizasyonu desteklemeyi amaçlayan ve giderek daha popüler hale gelen bu kavram tüm dünyada ilgi görmektedir (Liao ve ark., 2017). Google Trend'e göre, 2012 ve 2015 y1llarında "Endüstri 4.0" ve "Dördüncü Sanayi Devrimi" terimlerini içeren google aramaları yavaş yavaş baş göstermeye başlamıştır ve Aralık 2018 itibariyle bu konunun popülerliğini gösteren bir artış trendi mevcuttur. Bu, Endüstri 4.0'ın gelişmekte olan bir konu olduğunu ve daha fazla araştırmaya ihtiyaç duyduğunu göstermektedir. $\mathrm{Bu}$, araştırmacıların araştırma alanlarını geliştirmeleri ve yöneticilerin bu konu hakkında daha fazla şey keşfetmeleri ve Endüstri 4.0'1 şirketlerinde nasıl uygulayabileceklerini anlamaları için harika bir firsat olarak değerlendirilebilir. Ancak Endüstri 4.0'ın kesin bir tanımı henüz belirlenmemiştir. Lopes de Sousa Jabbour ve ark. (2018), Endüstri 4.0'1n temel özelliği, nesnelerin interneti ve elektronik cihazlar nedeniyle makineler, siparişler, çalışanlar, tedarikçiler ve müşteriler arasındaki bağlantıdır; sonuç olarak, firmalar merkezi olmayan kararlar ve otonom sistemler kullanarak ürünler üretebilirler.

Endüstri 4.0 aynı zamanda, internet standartlarına dayalı bir ağın parçası olan akıllı bileşenleri ve makineleri kapsayan bir ağ sistemini ve ayrıca bilgi ve iletişim teknolojilerinin üretime entegrasyonunu tanımlar. Makine mühendisliği, bilgi ve iletişim teknolojileri ve elektrik endüstrisinin önde gelen üç Alman şirketi olan VDMA, Bitkom ve ZVEI, 2014 baharında Endüstri 4.0 tanımlarını duyurmuştur. VDMA, Bitkom ve ZVEI'ye göre Endüstri 4.0, otonom olarak kontrol edilen dinamik bir üretim uygulayarak değer zincirlerinin optimizasyonunu hedefliyor (Kolberg ve Zühlke 2015). Endüstri 4.0 girişiminin, ürünlerin ve üretim sistemlerinin tasarımını, üretimini, işletimini ve hizmetini tamamen değiştireceğine inanılmaktadır. Öğeler, makineler ve insanlar arasındaki bağlantı ve etkileşim, üretim sistemlerinde süreçlerin hızını yüzde 30'a kadar hızlandıracak, süreçlerin verimliliğini yüzde 25'e kadar artıracaktır (Rüßmann ve ark., 2015).

Nesnelerin interneti, otonom robotlar ve büyük veri analitiği gibi pek çok dijital teknoloji, endüstri 4.0'ın merkezinde yer almaktadır ve bu teknolojiler üretimi yenilemeye ve temel üretim süreçlerinin dijitalleşmesinin ilerlemesine yardımcı olmaya devam etmektedir. Bu teknolojiler, önde gelen şirketler tarafından operasyonel gelişim planlarını kolaylaştırmak için uygulanmaktadır. Hızlı bir ivme oluşturmak ve stratejik bir vizyona ulaşmak için bu teknolojilerin şirketler tarafından uygulanması, hızlı geri dönüşler sağlamalı ve uygulanarak uzun vadeli kazanımlar sağlamalıdır. Birçok şirket, Endüstri 4.0 uygulamasının avantajlarından yararlanmıştır. Bununla birlikte, Endüstri 4.0'dan değer yaratmanın yeni yolları hala araştırılmaktadır. Yeni yöntem ve teknikler ortaya çıktıkça bu yeni yaklaşımın yaratacağı değer artacaktır (Brunelli ve ark., 2017).

Endüstriyel verimlilik, Sanayi devrimi'nin başlangıcından bu yana etkileyici bir gelişme göstermiştir. 19. yüzy1lda buhar motorunun icadıyla başlayarak, 20. yüzyılın ilk bölümünde elektrikle çalışan montaj hatları ve 1970 'lerde otomatik üretim gibi diğer güç kaynakları ve üretim yöntemleri, verimlilikte çarpıcı bir artışa yol açmıştır. Yıllar içinde, teknolojik yenilikler çoğaldı ve bilgi 
teknolojisini (BT), mobil iletişimi ve e-ticareti dönüştürmüştür.

En yeni dijital endüstriyel devrim olan Endüstri 4.0, dokuz teknoloji ayağı tarafından desteklenen çığır açan bir gelişmedir. Bağlı sistemler bu dönüşümün merkezinde yer alır. Sensörler, makineler, BT sistemleri ve iş parçaları, tüm değer zinciri boyunca birbirine bağlıdır ve bu bağlı sistemler, verileri analiz edebilir ve internet tabanlı protokoller aracılığıyla birbirleriyle iletişim kurabilirler. Veri analizi, sistemlerin arızayı tahmin etmesine, kendini yapılandırmasına ve ani değişikliklere uyum sağlamasına yardımcı olur. Endüstri 4.0, makineler arasında veri toplama ve analiz imkânı sağlar ve daha düşük üretim maliyetiyle daha yüksek kaliteli ürünler üreten hızlı, esnek ve verimli bir sistem sağlamaktadır. Sonuç olarak, Endüstri 4.0, endüstriyel büyüme hızı arttıkça üretim verimliliğini artırır. Verimlilikteki iyileşme, bir şirketin diğerlerine kıyasla rekabet avantajı kazanmasına yol açmaktadır (Rüßmann ve ark., 2015).

Dokuz temel Endüstri 4.0 teknolojisinden bazıları bugünün üretim sistemlerinde zaten kullanılıyor. Ancak, diğerleri üretim sürecini yeniden yapılandırmak için tasarlanmıştır. Örneğin, izole edilmiş ve optimize edilmiş hücreler, tedarikçiler, üreticiler ve son müşteriler arasındaki geleneksel üretim ilişkilerini değiştirerek daha fazla üretkenliğe yol açan tam entegre, otomatikleştirilmiş ve optimize edilmiş bir üretim akışı oluşturmak için bir araya gelecektir.

Bu temel unsurlara ek olarak, Pfohl ve ark. (2015), Endüstri 4.0'n karakteristik özelliklerine odaklanmış ve bunları kapsamlı literatür taramasının sonunda şu şekilde özetlemiştir; dijitalleşme, özerklik, şeffaflık, hareketlilik, modülerleştirme, ağ iş birliği ve sosyalleşme, esneklik, entegrasyon derecesi, merkezi olmayan kontrol ve gerçek zamanlı kullanılabilirlik.

Ayrıca firmalar ve kuruluşlar açısından Endüstri 4.0 için firmaların uygulaması gereken bazı temel özellikler aşağıda özetlenmiştir (Oesterreich ve Teuteberg, 2016);

- Tedarikçiden müşterilere değer ağları aracılığıyla bilgi ve iletişim sistemlerinin yatay entegrasyonu,

- Yüksek düzeyde özelleştirilmiş ürünleri minimum dahili işletme maliyetleriyle basitleştirmeyi başarmak için tüm değer zinciri için genel dijital entegrasyon,

- Akıllı üretim ortamında tüm süreç ve departmanlarla dikey entegrasyon. Genel olarak Endüstri 4.0 ortamı bakış açısıyla Deloitte raporuna göre (Schläpfer ve ark., 2015), Endüstri 4.0'ın önemi mobilite, şebeke, lojistik, evler ve binalar ve iş/sosyal ağ bağlantılarını içeren akıllı altyapılarla başlamaktadır. Bu unsurlar, nesnelerin interneti, hizmetlerin interneti, insanların interneti ve verilerin etkisi altındaki dijital dönüşüm için büyük önem taşımaktadır.

Bu nedenle Endüstri 4.0 paradigması sadece imalatla sınırlı olmayıp, lojistik gibi tedarik zinciri organizasyonunun aktörleri olan birçok bağımlı ve destekleyici sektörle ilişkilidir. Bu çalışma, Endüstri 4.0 ortamında sadece lojistik sektörüne odaklanmıştır. Bu nedenle aşağıdaki bölümde Endüstri 4.0'da lojistik sektörü ile ilgili literatür tartışılmıştır.

\section{ENDÜSTRI 4.0 VE LOJISTIK SEKTÖRÜ: LOJISTIKK 4.0}

Bir önceki bölümde açıklandığı gibi Endüstri 4.0 sadece üretim ortamını değil, endüstri ile ilgili tüm süreçleri ve hizmetleri de etkilemektedir. Sanayi ve hizmet faaliyetlerinin kilit unsurlarından biri olan lojistik sektörünün de yeni sanayi devrimlerinin teknolojik gelişmelerine göre değişmesi gerekmektedir. Öte yandan, lojistik sektörünün Endüstri 4.0 teknolojileri 1şığında incelenmesi konusunda mevcut literatürde hala kaynak eksikliği mevcuttur.

Lojistik sektörünün değerlendirilmesi Galindo (2016) tarafından sanayi devrimleri doğrultusunda özetlenmiştir. Lojistik sektörü değerlendirmesinin ilk aşaması için anahtar kelime taşımacıllğın 
mekanizasyonudur. Çünkü bu aşama, manuel araçlardan ve hayvan gücünden demiryolu ağlarına ve buharlı/uçak vardiyalarına geçişi temsil etmektedir. İkinci aşama olan lojistik 2.0, otomatik depolar, liman kargolarının mekanizasyonu, otomatik sıralama vb. gibi lojistik ekipmanların kullanılmasının başlangıcı olarak kabul edilir. Lojistik sektörü değerlendirmesinin üçüncü dalgası, sayısal olarak kontrol edilen makineler ve endüstriyel robotlar tarafından şekillendirilmiştir. Bu nedenle, lojistik 3.0'ın anahtar ifadesi, lojistik yönetim sistemleri olabilir. Son olarak, lojistik sektörünün değerlendirme zaman çizelgesinde gelinen aşama Endüstri 4.0'dan oldukça etkilenmekte ve çoğunlukla nesnelerin interneti ve hizmetlerin interneti teknolojilerinin değerlendirilmesine dayanmaktadır. Lojistik 4.0 terimi, Barreto ve ark. (2017) tarafindan lojistiğin siber fiziksel sistemlere dayalı yenilik ve teknolojilerle entegrasyonu olarak tanımlanmıştır.

Bilgi teknolojisi iletişimi, büyük veri kullanımı, nesnelerin interneti, otomasyon ve robotik, dijitalleşme, siber-fiziksel sistemler gibi ileri teknolojilere dönüşüm açısından Endüstri 4.0 zorluklarının üstesinden gelmek için; lojistik sektörünün iş profilleri, süreçler ve kullanılan teknolojiler açısından değiştirilmesi gerekmektedir. Bu değişikliklerin hem olumlu hem de olumsuz etkileri olması beklenmektedir. Daha yüksek standardizasyon, daha düşük manuel işgücü, daha şeffaf süreçler ve daha iyi iletişim, lojistik 4.0'ın potansiyel olumlu etkileri iken; daha yüksek yatırım ihtiyacı, altyapı maliyetleri ve uyum maliyetleri Lojistik 4.0'ın zorlukları olarak görülebilir (Szymańska ve ark., 2017).

Ayrıca Baretto ve ark. (2017) göre verimli Lojistik 4.0 uygulamaları için depo yönetim sistemleri, ulaşım yönetim sistemleri, akıllı ulaşım sistemleri, kaynak planlaması ve bilgi güvenliği gibi teknolojik uygulamalar zorunludur. Ayrıca lojistik sektörünün de Endüstri 4.0'1 şekillendiren en önemli teknolojilerden biri olan nesnelerin internetinden faydalanması beklenmektedir.

Hoffmann ve Rüsch (2017), Endüstri 4.0'daki lojistik süreçlerin fiziksel tedarik zinciri boyutu ve dijital değer zinciri boyutu olmak üzere iki ana boyutu olduğunu öne sürmüşlerdir. Fiziksel tedarik zinciri boyutu, otonom ve kendi kendini kontrol eden lojistik sistemleri ifade ederken, dijital veri değer zinciri boyutu, tüm tedarik zincirindeki fiziksel araçlardan veri toplama ve her türlü analitik için kullanılır.

\section{LOJISTIK 4.0'IN ORTAYA ÇIKIŞI}

İş süreçlerinin dijitalleşmesi, elektronik veri alışverişini teşvik etmeye yönelik ilk çabalarla 1960'larda başlamıştır. Bu süreçler, yeni uygulamalar ve değiş tokuş edilen bilgilerin akışını, hızını, güvenilirliğini ve güvenliğini iyileştiren teknolojilerin entegrasyonu ile zamanla daha karmaşı hale gelmiştir. Lojistik zincirindeki katılımcılar arasında veri yönetimi ve alışverişi, katma değerli hizmetlerin tasarımına katkıda bulunarak, müşterilerin ihtiyaçlarına yönelik önemli bir yenilik ve iç görü kaynağı olduğunu kanıtlamaktadır (Pérez ve Sanchez, 2019).

$\mathrm{Bu}$ nedenle uygulamalar, giderek daha karmaşık ve kapsamlı bir lojistik zinciri birbirine bağlayan ve besleyen, katılımcıların rekabet gücünü artıran ve mevcut altyapı ve hizmetlerin verimliliğini en üst düzeye çıkaran teknolojik bir iplik olarak görülmelidir. Bu teknolojik uygulamalar, altyapı hizmetlerinin verimliliğini, güvenliğini ve sürdürülebilirliğini geliştirmek, farklı katma değerli hizmetler için fırsatlar yaratmak ve olumsuz sosyal ve çevresel dışsallıkları azaltmak için farklı bilgi kontrol, iletim ve işleme teknolojilerini birleştirir ve koordine etmektedir (Pérez ve Sanchez, 2019).

Dördüncü sanayi devriminin ortasında, sürekli bilgi yönetimi ve gerçek zamanlı tedarik zinciri yönetimine olanak tanıyan hem aktörler hem de ülkeler arasında giderek belirsizleşen sınırlar ile hizmet kalitesine vurgu yaparak dış ticaret iş modeli bir kez daha değişmektedir. Yıkıcı bir teknoloji, yeni bir pazar yaratan veya mevcut bir pazarı önemli ölçüde dönüştüren, toplum tarafından daha önce günlük olarak kullanılan ürün veya hizmetlerin yerini alan veya ortadan kaldıran bir yeniliktir. Bu tür yıkıcı inovasyon, mevcut pazar lideri şirketlerden ziyade, piyasaya giren yabancılar ve girişimciler tarafından 
üretilme eğilimindedir (Voege, 2019).

Blok zinciri, nesnelerin interneti ve büyük veri gibi bir dizi teknoloji, işletme verimliliğini artırmak, üretimi talepteki değişikliklere hızla uyarlamak için gereken esnekliği sağlamak ve ilgili maliyetleri ve negatif dışsallıkları azaltmak amacıyla kurumsal sektörde iç içe geçerek ve yıkıcı değişiklikler üreterek dördüncü sanayi devrimini yönlendiriyor. Dördüncü sanayi devrimi için hizmet sunan Lojistik 4.0, zaman ve kaynakların optimizasyonu, tedarik zinciri izlenebilirliği, verilerin güvenliği ve bütünlüğü ve farklı insan ve dijital aktörler arasında uygun birlikte çalışabilirlik ile karakterizedir. Bu dijital ekosistem aynı zamanda yenilikçiliği ve sosyal ve çevresel olarak daha sürdürülebilir ticareti teşvik eden yeni bilgi tabanlı hizmetlerin ve iş modellerinin oluşturulmasını da desteklemektedir.

Tedarik zincirinin temsilcileri arasındaki iş birliği ve tüm lojistik zincirinin daha iyi görünürlüğü ve izlenebilirliği, kargo akışlarının gerçek zamanlı yönetimini ve altyapı ile mevcut insan ve teknolojik kaynakların daha iyi kullanımını kolaylaştırır. Büyük hacimli bilgilerin gerçek zamanlı olarak mevcudiyeti, kanıta dayalı karar vermeye fayda sağlar, böylece çalışma verimliliğini, ilgili maliyet ve hizmetlerde iyileștirmeleri ekonomik üretkenliği artırmaktadır.

Yeni bilgi tabanlı lojistik hizmetleri türlerinin önünü açan teknolojik değişiklikler, esas olarak, talepteki veya mevcut altyapıdaki değişiklikleri gerçek zamanlı olarak yönetmek ve optimize etmek için hizmetlerin ve sistemlerin entegrasyonu ile desteklenir, bu da maliyetleri ve taşıma sürelerini azaltır ve müşteri teslimat deneyimini geliştirir. Liman lojistiğindeki yıkıcı teknolojiler arasında robotik, yapay zekâ, nesnelerin interneti, otomasyon ve tabii ki blok zinciri yer alıyor. Bu unsurlar, diğer bilgi teknolojisi gelişmelerinin yanı sıra birbirleriyle veya bulut bilişim, coğrafi bilgi sistemleri, 5G ve liman topluluk sistemleri gibi diğer mevcut teknolojik araçlarla bir arada bulunur ve bağlantılıdır.

Üretim süreçlerinin konfigürasyonundaki esneklik ve talebe otomatik olarak uyum sağlama yeteneği, dördüncü sanayi devriminin özüdür (Lage, 2019). Birbirinden farklı verileri yakalamak, güvenli bir şekilde iletmek ve analiz etmek, dinamik ve sürekli olarak yeni optimizasyon süreçlerini tetikleyen rehberli kararlar almak için esastır.

\section{LOJISTIK 4.0 YÖNETIMİ İÇİN ANA TEKNOLOJILER}

$\mathrm{Bu}$ bölüm, lojistik planlamada iyileştirmeye ve ürün ve hizmetlerin üretimi yoluyla lojistik süreçlerde değer yaratmayı sağlayan farklı bilgi sistemlerinin entegrasyonuna izin veren lojistik sistemlerinde kullanılan temel bilgi ve iletişim teknolojilerinin tanımına, kapsamına ve etkisine değinmektedir.

Endüstri 4.0, tedarik zinciri, üretim ve yönetim gibi çeşitli alanlara, özellikle gerçek zamanlı olarak yanıt verebilmek için siber-fiziksel sistemlerin, nesnelerin internetinin, hizmetlerin internetinin, robotik, büyük veri ve bulut üretiminin kullanımını teşvik etmekte, böylece cihazlar, makineler, üretim modülleri ve ürünleri dahil etmekte ve bunları uygulamaktadır (Pereira ve Romero, 2017). Makine öğrenimi algoritmaları, yapay zekâ, iş analizi ve optimizasyon, özellikle dinamik optimizasyon, otomasyonu en üst düzeye çıkarmak için Endüstri 4.0'1 bir sistemde uygulamak için uygulanabilir tekniklerdir (Kolberg ve Zühlke, 2015).

Lojistik 4.0, küresel rekabetin ve değişen müşteri taleplerinin getirdiği değişimi sağlayabilmek için tüm teknolojik temellerin iş birliğine dayanmaktadır. Bu nedenle dijitalleşme, dikkatli yürütülmesi gereken bir süreçtir. Katmanlı üretim/3D baskı, arttırılmış gerçeklik, büyük veri analitiği, blockchain teknolojisi, bulut hizmetleri, işbirlikçi planlama, tahmin ve yenileme, insansız hava araçları, elektronik, veri değişimi, e-satınalma, kurumsal kaynak planlama, global konumlandırma sistemleri ve genel paket telsiz hizmetleri (GPS ve GPRS), pick-to-light and pick-by-voice, radyo 
frekansı, tanımlama, satış ve operasyon planlaması, nesnelerin interneti, ulaştırma yönetim sistemi, depo yönetim sistemi, giyilebilir teknolojiler ve dijital ikiz gibi yıkıcı teknolojiler, yüksek bağlantı ve mobil teknoloji yeteneklerini entegre etmeye başlamıştır ve lojistik için yeni bir yaklaşım ve teknoloji araştırma eğilimini temsil eden Endüstri 4.0 olarak adlandırılmaktadır.

\section{Katmanlı Üretim/3D Baskı}

Üç boyutlu modellerden elde edilen verilerden karmaşık geometrilere sahip çok çeşitli yapılar ve nesneler üretmek için katman katman malzeme birleşimini gerçekleştirmek için kullanılan bir teknolojidir. İşlem, birbiri üzerine oluşturulmuş ardışık malzeme katmanlarının basılmasından oluşur. Kapsam ve etki, kitlesel özelleştirme, üretimin yerelleştirilmesi, ürün geliştirme süresinin kısaltılması, müşterilerin değer yaratmada daha fazla bütünleştirilmesi ve bilgisayar destekli tasarım modellerinin ve evde müşteriler tarafından basılan ürünlerin satışı yoluyla envanterlerin ve nakliye maliyetlerinin azaltılmasını içerir (Durach ve ark., 2017).

\section{Arttırılmış Gerçeklik}

$\mathrm{Bu}$ teknoloji, diğerlerinin yanı sıra sanal görüntüler, grafikler ve bilgiler sağlayan giyilebilir cihazlar, bilgisayarlar ve akıllı telefonlardaki kameralar aracılığıyla dijital ve fiziksel dünyanın gerçek zamanlı olarak birleştirilmesini içerir. Depo yönetiminde potansiyel kullanımları, alım, depolama, toplama ve sevkiyat operasyonlarını ve montaj operasyonlarının desteğini, personel eğitimini ve ürün incelemesini içerir. Hataları azaltmaya yardımcı olur ve iş yerinde esnekliği, güvenilirliği, çalışma hızını, uyarlanabilirliği ve güvenliği artırır (Stoltz ve ark., 2017).

\section{Büyük Veri Analitiği}

Gelecekteki davranışların tahmin edilmesini sağlayan, verilerdeki davranış kalıplarını belirlemek için her türlü saklanan elektronik bilgiye gelişmiş istatistikler uygulayan teknolojik bir araçtır. Büyük veri ve iş analitiği içerir, bu nedenle veri yönetimi yaklaşımlarının geleneksel yeteneklerini aşan önemli miktarda ve çeşitli yüksek hızlı verileri işler. Büyük veri analitiği, organizasyonel stratejileri ve operasyonları sürekli olarak değerlendirmek ve iş planlaması için bir rehber sağlamak için becerileri, teknolojileri ve uygulamaları inceler. Kullanımları, istatistiksel ve operasyon analizi, tahmine dayalı modelleme, tahmin ve optimizasyon tekniklerine dayanan ürün geliştirme için stratejik yönetimden müşteri hizmetlerine kadar uzanır. Tedarik zincirinin görünürlüğünü ve şeffaflığını artırır ve operasyonların ve bakımın verimliliğini artırmak için bilginin kullanılabilirliğini artırır. Aynı şekilde, entegrasyonu ve iş birliğini teşvik eder (Kache ve Seuring, 2017).

\section{Blockchain Teknolojisi}

Blockchain teknolojisi, işlemleri ve bilgileri yönetir ve tedarik zinciri katılımcıları arasındaki varlıkların ve işlemlerin geçmişini gerçek zamanlı olarak depolayan dağıtılmış bir defter veya veri tabanı olarak tanımlanabilir. İşlemlerin eşzamanlı olarak kaydedilmiş bir versiyonunu geliştirir ve farklı bilgisayarlardan aynı anda birden fazla değişiklik yapıldığında ortaya çıkan çakışmaları önlemeye yardımcı olur. Blockchain teknolojisi, gelişmekte olan teknolojilerin ekosisteminin bir parçasıdır ve üçüncü taraf doğrulamasına gerek kalmadan bilgisayar algoritmalarını kullanarak işlemleri dakikalar içinde işleyebilir ve tamamlayabilir. Bu nedenle, veri bütünlügünü koruyarak, gerekli bilgilerin anında paylaşılmasına ve süreçlerin programlanabilir ve otomatik kontrolünü sağlayarak birçok manuel işlem, belgelerin fiziksel olarak doğrulanması ve aracı/broker ihtiyacını ortadan kaldırır. Blockchain'in tedarik zincirindeki rolü, ürünleri hammaddeden bitmiş ürünlere kadar takip eden organizasyonlar arası bir sistem olarak hareket etmektir, akıllı sözleşmeleri ve tedarik zinciri finansmanını yönetir ve bir tedarik zincirinin artan görünürlüğünü ve izlenebilirliğini sağlar (Gurtu ve Johny, 2019). 


\section{Bulut Hizmetleri}

Bulut hizmetleri ve özellikle bulut merkezleri, bilgisayar olanaklarını, depolama aygitlarını ve paylaşılan uygulamaları kullanarak, isteklere ve kullanım kolaylıklarına göre her zaman ve her yerde internete erişmek için bir bilgisayar modeli sağlar. Bu, hizmet olarak altyapı, hizmet olarak platform ve hizmet olarak yazılım aracılığıyla gerçekleştirilebilir. Bulut hizmetleri, lojistik bilgilerinin depolanması, alınması, danışmanlığ1 ve güvenli korunması gibi hizmetler sunar. Ek olarak, lojistik operasyonları desteklemek için lojistik bilgilerinin akıllı işlenmesi ve analizini sunarlar; operasyonların planlanması, tasarımı ve simülasyonu için lojistik yazılım alışverişini kolaylaştırmak ve diğerlerinin yanı sıra kalite takibi ve izlenebilirlik, konteyner ve ürün takibi ve tehlikeli yüklerin genel olarak izlenmesi için nesnelerin interneti platformlarının kurulmasına izin verir (Xu ve ark., 2012).

\section{İşbirlikçi Planlama, Tahmin ve Yenileme (CPFR)}

Bir şirketin lojistik sistemlerinin, işbirlikçi yaklaşımlar yoluyla tedarikçilerin ve müşterilerinkilerle entegrasyonunu temsil eden bir araçtır. Satıcı tarafından yönetilen envanter ve verimli tüketici yanıt sistemlerinin evrimi olarak kabul edilir. Üretim ve tedarik planlaması, talep tahmini ve envanter yenileme dahil olmak üzere çeşitli tedarik zinciri süreçlerini koordine eder. İşbirliğine dayalı planlama, tahmin ve yenileme, envanter doğruluğunu ve yanıt verme hızını artırır; ortaklarla ilişkileri güçlendirir, tedarik zincirinin döngü sürelerini ve genel maliyetlerini azaltır; gelirleri ve kârları artırır ve diğerlerinin yanı sıra kamçı etkisini azaltır (Panahifar ve ark., 2015).

\section{Dronlar}

Dronlar veya insansız hava araçları, karayolu altyapısına bağlı olmadan seyahat etme kabiliyetine sahiptir ve perakendecilerin bireysel siparişler için özel hava araçları kullanarak benzeri görülmemiş teslimat hızı ve uyarlanabilir teslimat süreleri sunmalarını sağlar. Genişleyen çevrimiçi perakende sektörü, dronların gelişmiş kapasitesi, güvenilirliği ve maliyet etkinliği ve teslim alma ve teslimat hizmeti sağlayıcıları arasındaki yüksek rekabet gibi faktörler, önümüzdeki birkaç yıl içinde teslimat uygulamaları için dron kullanımını artıracaktır. İHA'ların hareketli bir üs görevi gören başka bir araçla ortak kullanımı, iniş konumlarının belirlenmesini karmaşık hale getirme pahasına dronların genişletilmiş bir hareket yarıçapı üzerinde çalışmasına izin veren en çok yönlü çözümdür. Perakendeciler, dağıtma sürelerini azaltmak için yüksek hızlı ve özel teslimat yeteneklerini merkezden uzaklaştırma yoluyla artırabilirler. Dron dağıtım sistemlerinin karşılaştığı bazı teknik zorluklar, her bir drone'a güç sağlayan elektrik pillerinin sınırlı ömrü ile ilgilidir. Lojistik sektöründe insansız hava araçlarının uygulanmasının önündeki en kritik engeller teknolojik gelişmeler, hükümet düzenlemeleri, mahremiyet ve güvenliğe yönelik tehditler, kamu algıları ve psikolojik ve çevresel sorunlardır (Şah ve ark., 2020).

\section{Elektronik Veri Değişimi}

Bir şirketin bilgi sisteminden tedarikçisinin bilgi sistemine iş verilerinin transferini temsil eder. İşlemleri minimum hatayla, en yüksek hızda ve en düşük maliyetle gerçekleştirmek için farklı bilgisayar sistemleri ve dilleri tarafından kullanılan veri yapılarını standartlaştırır ve bunu bir tedarik zincirinin üyeleri arasında şeffaf bir şekilde yapar. GPS sensörlerinin desteği ile ürünlerin son tarih ve teslimat sürelerinin önceden bilinmesini kolaylaştırarak tolere edilebilir tahmin hataları sunar. Lojistik süreçlerinde teknolojilerin benimsenmesi için ortaklarla olumlu ilişkiler kurulmasını sağlar (Gunasekaran ve ark., 2017). Ayrıca ayrıntılı gönderi bilgilerini müşteriye önceden ileten gelişmiş gönderi bildiriminin uygulanmasını da kolaylaştırır.

\section{E-Satınalma}

Siparişler, kabul, satın alma sonrası incelemeler, ihaleler, açık artırmalar ve müzakereler gibi işlemler de dâhil olmak üzere bir kuruluşta mal ve hizmet tedarik sürecinin her aşamasının 
entegrasyonunu ve elektronik uygulamasını temsil eder. Beş farklı şekilde karşımıza çıkar: e-sipariş, esatın alma, e-ihale, e-açık artırma ve e-bilgilendirme. Tedarikçilerin daha iyi yönetimine ve kontrolüne, maliyet ve toplam satın alma süresinden tasarruf, güç dağıtma ve piyasa verilerine kolay erişim sağlar. Ayrıca tedarik zincirinde karar vermeyi, müşteri hizmet düzeylerini, iletişimi ve iş birliğini geliştirir; satın alma sürecini basitleştirir ve standartlaştırır, düzenlemelere ve yasalara uyumu artırır; süreç hatalarını en aza indirir ve çalışanlar arasındaki yolsuzluğu azaltır (Tiwari ve ark., 2019).

\section{Kurumsal Kaynak Planlama}

Bilgi sistemi, bir şirketteki tüm işlevsel alanları ve iç süreçleri dış süreçlerle ilişkilendirerek müşteriler ve tedarikçiler arasında yakın bir ilişki geliştirir. Tedarik zinciri ortakları arasındaki bilgi akışını geliştirerek bilgi paylaşımına izin verir. Modüller aracılığıyla, bir organizasyon içinde verilere gerçek zamanlı olarak erişime ve verilerin depolanmasına izin verir ve ayrıca analiz ve yönetim işlevlerine olanak tanır. Ürün tasarımı, bilgi depolama, malzeme planlaması, kapasite planlaması, iletişim sistemleri, finans, insan kaynakları ve envanter yönetimi dahil olmak üzere bir şirket için tüm kaynak planlamasını kapsar (Özcan ve Çimtay, 2016).

\section{Global Konumlandırma Sistemleri ve Genel Paket Telsiz Hizmetleri (GPS ve GPRS)}

GPS, her türlü hava koşulunda çalışabilen bir konumlandırma teknolojisidir. Tedarik zincirinde bir aracın veya yükün yerini sağlamak için yüksek hassasiyet ve hızlı yanıt sunar. GPRS, daha yüksek iletim hızı ve veri paketlerinin değiştirilmesi gibi avantajlar sunan, GSM şebekelerine dayalı bir iletişim teknolojisidir. GPS ve GPRS'in bir kombinasyonu genellikle alarm sistemlerine ve kargo aracı konum izlemesine uygulanır. Radyo frekansı tanımlama gibi teknolojilerle bağlantılı olarak, ürün bilgilerini kaydetmek için radyo frekansı tanımlaması kullanıldığından, ürün toplama ve taşıma için akıllı ve dinamik lojistik sistemlerin oluşturulmasına olanak tanır. Bu teknolojiler, nesnelerin internetinin ana sağlayıcılarıdır ve her bir taşıma biriminin konumunun gerçek zamanlı olarak izlenmesine izin verir (Naumova ve ark., 2020).

\section{Pick-to-Light ve Pick-by-Voice}

Pick-to-Light, 1şık sinyalleriyle toplama operatörlerini (toplayıcıları) destekleyen bir sipariş toplama teknolojisidir. Pick-by-Voice, toplama sürecini kontrol etmek ve yönlendirmek için ses ve sesi kullanan bir teknolojidir. Bu teknolojik araçlar, toplama operatörlerinin çalışmasını kolaylaştırdıkları ve sipariş toplamanın üretkenliğini ve kalitesini artırdıkları için geniş bir uygulamaya ve dünya çapında kabule sahiptir. Bağımsız toplama sistemlerine ve farklı toplama sistemi bölgelerine uyarlanabilirler (de Vries ve ark., 2015).

\section{Radyo Frekansı Tanımlama (RFID)}

Radyo frekansı tanımlama, bilgilerin radyo dalgaları, etiketler ve okuyucular aracıllğıyla iletilmesinden sorumludur, böylece toplanan bilgiler, ticari uygulamalarda işlenmek ve kullanılmak üzere radyo frekansı tanımlama ara yazılımına iletilir. Radyo frekansı tanımlama, tedarik zincirinin üretim, depolama ve nakliye süreçlerindeki verilerin toplanmasına, yönetilmesine ve analiz edilmesine yardımcı olur. Ek olarak, lojistik operasyonlardan büyük miktarda bilgi toplayarak büyük veri analitiği gibi veri yönetimi süreçlerine olanak tanır. Radyo frekansı tanımlama teknolojileri, bilgilerin gerçek zamanlı olarak görünürlüğünü ve izlenebilirliğini iyileştirir, tedarik zincirinin farklı dağıtım alanlarındaki envanter seviyesini tanımlar ve ürün hareketlerini takip eder. Ek olarak, radyo frekansı tanımlama, üretim ve lojistik kaynaklarını, her yerde bulunan bir ortam oluşturmak için bilgi yakalama ve etkileşim ve akıl yürütme yeteneğine sahip ak1llı nesnelere dönüştürür (Zhong ve ark., 2015).

\section{Satış ve Operasyon Planlaması}

Farklı iş planlarını, arz ve talebi dengelemek ve her bir şirketin ve tüm tedarik zincirinin stratejik 
planları ve operasyonel planları arasında bağlantılar oluşturmak için bir dizi entegre plan halinde birleştiren bir karar verme destek aracıdır. Müssteri odaklı pazarlama planlarını entegre ederek sürekli rekabet avantaj1 elde etmek için bir işi stratejik olarak yönetme yeteneği sağlar. Satış ve operasyon planlaması, satış, pazarlama, ürün geliştirme, satın alma ve finans planlarını, bir şirketin işlevsel faaliyetlerine aylık veya daha sık olarak dağıtılan benzersiz bir organize taktikler setinde birleştirir. $\mathrm{Bu}$, iş ortamından kaynaklanan değişiklikleri azaltarak daha esnek bir tedarik zinciri sağlar (Pedroso ve ark., 2016).

\section{Nesnelerin İnterneti (IoT)}

Sıradan nesneleri ve ürünleri internete bağlayarak veri iletmelerini ve almalarını sağlar. Fiziksel ve sanal nesnelerin kimlikleri ve fiziksel özellikleri olduğu ve akıllı arayüzler aracılığıyla bir bilgi ağına entegre edildiği standart ve birlikte çalışabilir iletişim protokollerini kullanan kendi kendini yapılandırma yeteneklerine sahip bir altyapıya dayanmaktadır. Lojistikte, nesnelerin interneti teknolojileri tedarik zinciri boyunca farklı varlıkları birbirine bağlar. Bu bağlantılardan üretilen veriler, operasyonların gerçek zamanlı görünürlüğünü sağlar ve yeni değer kaynakları oluşturur. Lojistik için nesnelerin interneti çözümleri, ürünlerin gerçek zamanlı olarak tam olarak izlenmesini sağlamak için sensörleri radyo frekansı tanımlaması ve GPS ile entegre ederek, ürünlerin müşterinin istediği koşulda varmalarını sağlar (Chuang ve ark., 2017).

\section{Ulaştırma Yönetim Sistemi}

Diğerlerinin yanı sıra kargo konsolidasyonu, nakliye, belge yönetimi, ürünlerin teslimi ve toplanması, rota planlaması, kargo denetimleri ve sipariş görünürlüğü ile ilgili görevlerin planlanması, yürütülmesi, izlenmesi ve kontrolüne yardımcı olmak için nakliye şirketleri tarafından kullanılan bir sistemdir. Ulaşım yönetim sistemi, hizmet noktalarını, her araç için rotaları, araç ve sürücülerin toplam kapasitesini, seyahat mesafesini ve toplam teslimat süresini belirler. Yükün müzakere ve denetimini, taşıma modu seçimini, multimodal taşımayı, durakların zamanını ve sırasını tahmin etmeyi, belge hazırlamayı ve kargo konsolidasyon planlamasını destekler ve ekonomik ve ekolojik maliyetleri en aza indirir (da Silva, 2018).

\section{Depo Yönetim Sistemi}

Alım, yerleştirme, depolama, sipariş toplama ve sevk süreçleri dahil olmak üzere depolarda ve dağıtım merkezlerinde süreç planlama, yürütme ve kontrolü destekleyen bir sistemdir. Radyo frekansı tanımlama, kablosuz sensör ve aktüatör ağları, nesnelerin interneti ve bulut bilişim gibi standart teknolojilerin kullanımına dayalı olarak insanlar, akıllı makineler ve robotlar arasındaki iş birliğini desteklemek için siber-fiziksel sistemlerle entegre edilebilir. Depo yönetim sistemi, firmaların tedarik, üretim, depolama ve dağıtım faaliyetlerinde kullandıkları bilgi altyapılarının oluşturulmasını kolaylaştırmaktadır. Ticari depo yönetim sistemi, depoda operasyon planlama ve izlenebilirlik ile personel ve malzeme taşıma ekipmanının çeşitli görevlere atanması için çok çeşitli çözümler içerir (Correa ve ark., 2010).

\section{Giyilebilir Teknolojiler}

Bilgisayarları ve gelişmiş elektronik teknolojileri içeren giysi ve aksesuarları kapsar. Giyilebilir teknoloji cihazları, vücutta rahatça kullanılmak üzere tasarlanmış elektronik teknolojileri veya bilgi işlem cihazlarını ifade eder. Operatörler, makineler ve üretim sistemleri arasında dinamik, güvenilir ve gerçek zamanlı etkileşimi desteklemek için insan-siber-fiziksel ortak yaşam kurarlar. Bu teknolojiler, sanal dünya ile gerçek dünya etkileşimini mümkün kılar diğerlerinin yanı sıra sensör eldivenleri, radyo frekansı tanımlama okuyucuları, akıllı saatler, gözlükler, yüzükler, kulplar, kulaklıklar, kemerler, kalemler ve ayakkabılara dayanmaktadır. Bu nesneler hafif ve basit olmaları ile karakterize edilir ve 
operatörün çalışmasına müdahale etmeyen eller serbest çalışmayı garanti eder (Kong ve ark., 2018).

\section{Dijital İkiz}

Dijital ikiz, fiziksel bir varlığın dijital temsili ve hatta çok daha fazlasıdır (Wohlfeld, 2019). Bir varlığın yaşam döngüsü boyunca işlenmesi için gerekli tüm bilgileri sağlayan kapsamlı bir fiziksel ve işlevsel tasvirini temsil etmektedir (Boschert ve Rosen, 2016). Dijital bir modelde, fiziksel ve dijital nesne arasında yalnızca manuel bir veri akışı bulunmaktadır. Fiziksel nesnedeki bir değişikliğin dijital nesne üzerinde hiçbir yansıması yoktur ve bunun tersi de geçerli olmaktadır. Dijital bir gölgede, en az bir yönde otomatik bir veri akışı vardır, bu sayede fiziksel nesnenin değişimi dijital nesnenin değişmesine yol açmaktadır. Ancak, bu durum tersi için geçerli değildir. Dijital ikizde, iki nesne arasındaki veri akışı otomatiktir. Böylece, fiziksel nesnede bir değişiklik, doğrudan dijital nesnede bir değişikliğe yol açar ve bunun tersi de geçerlidir (Kitzinger ve ark., 2018). Dijital ikizlerin kullanımı, varlıklar ve farklı sistemler arasında gerçek zamanlı iletişim sağlamaktadır. Lojistikle ilgili olarak, veri toplama tek başına büyük bir zorluk teşkil etmemektedir. Buradaki belirleyici faktör, gerçek katma değer sunabilmek için bu verilerin nasıl daha fazla işlenmesi gerektiğidir. Bu kapsamda, ilgili uygulamaya tam olarak uyarlanmış temel performans göstergeleri yardımıyla katma değer yaratılmaktadır. Kullanılan sensörlere bağlı olarak, aynı veri kaynaklarından gerçek zamanlı olarak, tam olarak ilgili süreç için gerektiği gibi farklı temel performans göstergeleri belirlenebilmektedir. Bu teknoloji, lojistik için önemli bir potansiyel sunmakta ve hedeflenen karar vermeye katkıda bulunmaktadır (Wang ve ark., 2016).

\section{SONUÇ}

Dördüncü sanayi devrimi ile ilişkili süregelen teknolojik değişimler, üretim sistemi ve çalışma biçimleri de dâhil olmak üzere günlük yaşamın tüm alanlarını etkileyerek dünyayı dönüştürme kapasitesine sahiptir. Lojistik bu paradigma değişiminin bir parçası olduğundan, yeni teknolojik ortama uyumu kolaylaştırmak için yeni araçlara ve bilgiye ihtiyaç vardır. Teknoloji kendi başına bir amaç değil, nesiller arası eşitlikle mevcut kalkınma taleplerini karşılamak ve ihtiyaç duyulan lojistik operasyonların rekabet edebilirliğini ve sürdürülebilirliğini geliştirmek için bir araçtır. Çevremiz mekân, insan ve zaman adı verilen üç olgu ile şekillenmektedir ve daha önce zaman kısıtlamasından seri üretim aracıllı̆ı ile kurtulmak mümkün olmuştur. Endüstri 4.0, bu olgulardan mekânın yok edilmesini öngörüyor ve çok hızlı gerçekleşiyor. Endüstri 1.0'1n tamamlanması 4 bin 300 yıl, Endüstri 2.0'den 3.0'e geçmek 70 yıl, Endüstri 3.0'ten 4.0'e geçmek ise 45 y1l almış. Bu nedenle ayak uydurmaktan ziyade süratle ilerleyen dijitalleşmenin bir parçası olabilmek için Lojistik 4.0'ın temelini oluşturan teknolojilerin uygulayıcısı olmak gerekmektedir. Değiş̧ime bu açıdan yaklaştığımızda, hammadde tedariğinden üretim hattına, üretim hattından tüketim noktalarına kadar Endüstri 4.0 çerçevesinde oluşan değer zincirleri, doğal olarak lojistik sektöründeki dönüşümü tetikleyecektir. Endüstri 4.0'ın ihtiyaçlarına göre değer zincirine entegrasyonu güçlendirecek uygulamalar önümüzdeki dönemde gündeme gelecek en önemli konuların başında gelmektedir. Aslında süreçleri otomatik olarak kontrol eden bilgisayar destekli sistemler sayesinde birçok taşıma süreci kontrol edilmektedir.

Küreselleşme, rekabet ve iş teknolojilerinin gelişimi, endüstrileri düşük maliyetle, daha kaliteli ürünler üretmeye teşvik etti. Bu, lojistik verimlilikle ilgili olarak üretken organizasyonlar arasında önemli bir ayrım yapabilmek için hızlı teknolojik benimsemeyi gerektirmektedir. Endüstri 4.0 temelde üretimi derinden etkileyen bir süreçtir. Üretim ve lojistikten ayrı düşünmek mümkün olmadığı için tüm dünyada etkisini göstermeye başlayan Endüstri 4.0'ın lojistik sektöründe iş yapış şeklini yeniden belirleyeceğini öngörebiliriz. Lojistik 4.0'ın temeli aslında bir yapay zekâ ve şirketlerimizin birer bilgi teknoloji şirketi olarak dönüşümüdür. Endüstri 4.0, lojistiğin 7. hattı dediğimiz doğru ürünün, doğru miktarda, doğru şekilde, doğru zamanda, doğru kaynakta, doğru şekilde ve doğru fiyatta tedarik edilmesinin tüm aşamalarını etkileyecektir. Çünkü Endüstri 4.0'ın temeli, tüm süreçlerin birbirleriyle 
gerçek zamanlı iletişim halinde olmasıdır (Küntay ve ark., 2017).

$\mathrm{Bu}$, şirketlerin işbirliğine dayalı planlama, tahmin ve ikmal, elektronik veri değişimi, e-tedarik, kurumsal kaynak planlaması, küresel konumlandırma sistemleri ve genel paket radyo hizmetleri, pickto-light ve pick-by-voice, radyo frekansı tanımlama, satış ve operasyon planlaması, ulaşım yönetim sistemleri ve katmanlı imalat, artırılmış gerçeklik, büyük veri analitĭgi, bulut hizmetleri, giyilebilir teknoloji, nesnelerin interneti ve dijital ikiz dâhil olmak üzere Lojistik 4.0'1n yıkıcı teknolojilerine sahip depo yönetim sistemi gibi geleneksel teknolojilerin benimsenmesini göz önünde bulundurarak, teknolojik altyapıyı edinme, güncelleme ve sürdürme konusunda önemli yatırımlar yapmaları gerektiği anlamına gelmektedir.

$\mathrm{Bu}$ durum, verimliliği artırmak ve müşterilerin ve tüketicilerin gereksinimlerini karşılamak için Lojistik 4.0'a geçişi sağlamak için lojistik süreçlerde benimsenen teknolojilerin tamamlanması ve güncellenmesi konusunda zorluklar yaratmaktadır. Bu yaklaşım, lojistik sistemlerin müşterilere hızlı bir şekilde yanıt vermesini, siparişlerin gerçek zamanlı olarak izlenebilirliğini ve görünürlügünü artırmasını ve tedarik zincirindeki diğer ajanlarla iş birliğine dayalı karar vermeyi kolaylaştırmasını sağlamaktadır.

Son olarak, üretim araştırmalarında '4.0' ifadesi üzerinde geniş bir fikir birliği var, ancak lojistiğin bu ifadeyi sistematik olarak benimsemediği ve Endüstri 4.0 ile ilgili artan miktarda bilimsel literatür olmasına rağmen, lojistik sistematik olarak ele alınmadığ 1 görülüyor. Bu inceleme, akıllı lojistik sistemleri ve endüstriyel dijitalleşme alanındaki çalışmaları birbirine bağlamak için bir temel sağlayabilir.

\section{KAYNAKÇA}

Ardito, L., Petruzzelli, A. M., Panniello, U., \& Garavelli, A. C. (2018). Towards Industry 4.0: Mapping digital technologies for supply chain management-marketing integration. Business Process Management Journal.

Barreto, L., Amaral, A., \& Pereira, T. (2017). Industry 4.0 implications in logistics: an overview. Procedia Manufacturing, 13, 1245-1252.

Boschert, S., \& Rosen, R. (2016). Digital Twin-The Simulation Aspect. Mechatronic Futures, 59-74. https://doi.org/10.1007/978-3-319-32156-1_5

Brunelli, J., Lukic, V., Milon, T., \& Tantardini, M. (2017). Five Lessons from the Frontlines of Industry 4.0. Boston Consulting Group. https://web-assets.bcg.com/img-src/BCG-Five-Lessons-from-theFrontlines-of-Industry-4.0-Nov-2017 tcm9-175989.pdf

Chuang, C-H., Lee, D-H., Chang, W-J., Weng, W-C., Shaikh, M.O., \& Huang, C-L. (2017). Real-time monitoring via patch-type piezoelectric force sensors for internet of things-based logistics. IEEE Sensors Journal, 17(8), 2498-2506.

Coleman, D.C. (1956). Industrial growth and industrial revolutions. Economica, 23(89): 1-22.

Commission, E. (2017). Germany: Industry 4.0. https://ec.europa.eu/growth/toolsdatabases/dem/monitor/sites/default/files/DTM_Industrie\%204.0.pdf

Correa, A.A., Gómez, R.A., \& Cano, J.A. (2010). Warehouse management and information and communication technology. Estudios Gerenciales, 26(117), 145-171.

da Silva, F.A. (2018). Evaluation of transportation management system in logistic operations in a beverage company. Gestão da Produção, Operações e Sistemas, 13(2), 1-20.

de Sousa Jabbour, A. B. L., Jabbour, C. J. C., Godinho Filho, M., \& Roubaud, D. (2018). Industry 4.0 and the circular economy: a proposed research agenda and original roadmap for sustainable operations. Annals of Operations Research, 270(1), 273-286.

de Vries, J., de Koster, R., \& Stam, D. (2015). Exploring the role of picker personality in predicting 
picking performance with pick by voice, pick to light and rf-terminal picking. International Journal of Production Research, 7543, 1-15.

Denyer, D., \& Tranfield, D. (2009). Producing a systematic review. In D. A. Buchanan \& A. Bryman (Eds.), The sage handbook of organizational research methods (pp. 671-689). Sage Publications Ltd. https://psycnet.apa.org/record/2010-00924-039

Domingo Galindo, L. (2016). The Challenges of Logistics 4.0 for the Supply Chain Management and the Information Technology [Master's thesis, NTNU]. NTNU Open. http://hdl.handle.net/11250/2396477

Drath, R., Horch, A. (2014). Industrie 4.0: Hit or hype? [industry forum]. IEEE Industrial Electronics Magazine, 8(2): 56-58.

Durach, C.F., Kurpjuweit, S., \& Wagner, S.M. (2017). The impact of additive manufacturing on supply chains. International Journal of Physical Distribution and Logistics Management, 47(10), 954 971.

Forum, W. E., (2016). The fourth insutrial revolution what it means and how to respond. https://www.weforum.org/agenda/2016/01/the-fourth-industrial-revolution-what-it-means-andhow-to-respond.

Gunasekaran, A., Subramanian, N., \& Papadopoulos, T. (2017). Information technology for competitive advantage within logistics and supply chains: a review. Transportation Research Part E: Logistics and Transportation Review, 99, 14-33.

Gurtu, A., Johny, J. (2019). Potential of blockchain technology in supply chain management: a literature review. International Journal of Physical Distribution and Logistics Management, 49(9), 881900.

Hermann, M., Pentek, T., \& Otto, B. (2016). Design principles for industrie 4.0 scenarios. In System Sciences (HICSS). 2016 49th Hawaii International Conference, 3928-3937.

Hofmann, E., \& Rüsch, M. (2017). Industry 4.0 and the current status as well as future prospects on logistics. Computers in Industry, 89, 23-34.

Jazdi, N. (2014). Cyber physical systems in the context of Industry 4.0. IEEE International Conference on Automation, Quality and Testing, Robotics, 1-4.

Kache, F. \& Seuring, S. (2017). Challenges and opportunities of digital information at the intersection of big data analytics and supply chain management. International Journal of Operations \& Production Management, 37(1), 10-36.

Kagermann, H., Wahlster, W. \& Helbig. J. (2013). Recommendations for implementing the strategic initiative Industrie 4.0. In: Final report of the Industrie Working Group. Acatech: Frankfurt am Main.

Kamble, S. S., Gunasekaran, A. \& Gawankar, S. A. (2018). Sustainable Industry 4.0 framework: A systematic literature review identifying the current trends and future perspectives. Process Safety and Environmental Protection, 117, 408-425.

Kolberg, D. \& Zühlke, D. (2015). Lean Automation enabled by Industry 4.0 Technologies. IFACPapersOnLine, 48(3): 1870-1875.

Kolberg, D., \& Zühlke, D. (2015). Lean automation enabled by industry 4.0 technologies. IFACPapersOnLine, 48(3), 1870-1875.

Kong, X. T. R., Luo, A., Huang, G. Q. \& Yang, X. (2018). Industrial wearable system: the humancentric empowering technology industry 4.0. Journal of Intelligent Manufacturing, 30, 2853-2869.

Kritzinger, W., Karner, M., Traar, G., Henjes, J., \& Sihn, W. (2018). Digital Twin in manufacturing: A 
categorical literature review and classification. IFAC-PapersOnLine, 51(11), 1016-1022. https://doi.org/10.1016/j.ifacol.2018.08.474

Küntay, B., Yalçın, Ş., Nuhoğlu, Ç., Eldener, E., Tulgar, A., Barlın, A. Herdem, C., Çak, G., Güler, K., Dölen, İ., Erkeskin, T., Altaltan, U., Rota, Y. \& Zagaia, V. (2017). Endüstri 4.0 ortak ak11 toplantılar1: lojistik sektörünün yol haritası. Turkishtime. http://www.turkishtimedergi.com/wpcontent/uploads/2019/08/BAU\%202\%20Lojistik\%20Sekt\%C3\%B6r\%C3\%BC.pdf

Lage, O. (2019). Blockchain: From Industry 4.0 to the Machine Economy. IntechOpen. https://www.intechopen.com/online-first/blockchain-from-industry-4-0-to-the-machineeconomy

Liao, Y., Deschamps, F., Loures, E. D. F. R., \& Ramos, L. F. P. (2017). Past, present and future of Industry 4.0-a systematic literature review and research agenda proposal. International journal of production research, 55(12), 3609-3629.

Macdougall, W. (2014). Industrie 4.0 smart manufacturing for the future. mechanical \& electronic technologies. germany trade \& invest, 40 .

Medyakova, E. M., Kislitskaya, N. A., Kudinova, S. G., \& Gerba, V. A. (2020). COVID-19 as a trigger for global transport infrastructure digitalization. IOP Conference Series: Materials Science and Engineering, 918(1), 012227. https://doi.org/10.1088/1757-899x/918/1/012227

Nandi, S., Sarkis, J., Hervani, A. A., \& Helms, M. M. (2021). Redesigning Supply Chains using Blockchain-Enabled Circular Economy and COVID-19 Experiences. Sustainable Production and Consumption, 27, 10-22. https://doi.org/10.1016/j.spc.2020.10.019

Naumova, O.N., Ivanova, EA., Prischepa, A.S., Soshnev, A.N., \& Fedyukovsky, A.A. (2020). Analysis of the influence of information and communication technologies on the development of transport and logistics activities in the regions of the arctic zone of the rf. IOP Conference Series: Earth and Environmental Science, 434(1).

Oesterreich, T. D., \& Teuteberg, F. (2016). Understanding the implications of digitisation and automation in the context of Industry 4.0: A triangulation approach and elements of a research agenda for the construction industry. Computers in Industry, 83, 121-139.

Özcan, E., \& Çimtay, M.A. (2016). Software application in supply chain management and examining of productivity effects of use "ERP" in enterprises. Ege University International Logistics and Supply Chain Congress, 402-408.

Panahifar, F., Heavey., Byrne, P.J., \& Fazlollahtabar, H. (2015). A framework for collaborative planning, forecasting and replenishment (CPFR): state of the art. Journal of Enterprise Information Management, 28(6), 838-871.

Paprocki, W. (2016). How transport and logistics operators can implement the solutions of Industry 4.0. TranSopot Conference. Springer, 185-196.

Pedroso, C.B., da Silva, A.L., \& Tate, W.L. (2016). Sales and operations planning (S\&OP): insights from a multi-case study of brazilian organizations. International Journal of Production Economics, 182, 213-229.

Pereira, A. C., \& Romero, F. (2017). A review of the meanings and the implications of the Industry 4.0 concept. Procedia Manufacturing, 13, 1206-1214.

Pérez, G., \& Sánchez, R. (2019). Logistics for production, distribution and trade (No. 369). FAL Bulletin, Economic Commission for Latin America and the Caribbean. http://hdl.handle.net/11362/44899

Pfohl, H. C., Yahsi B., \& Kurnaz T. (2015). The impact of industry 4.0 on the supply chain. İçinde W. Kersten, T. Blecker, \& C. M. Ringle (Eds.), Sustainability in logistics and supply chain 
management. (21 $1^{\text {st }}$ ed., pp. 31-58). Proceedings of the Hamburg International Conference of Logistics (HICL).

Queiroz, M. M., Ivanov, D., Dolgui, A., \& Fosso Wamba, S. (2020). Impacts of epidemic outbreaks on supply chains: mapping a research agenda amid the COVID-19 pandemic through a structured literature review. Annals of Operations Research. Published. https://doi.org/10.1007/s10479-020$\underline{03685-7}$

Raj, A., \& Sah, B. (2019). Analyzing critical success factors for implementation of drones in the logistics sector using grey-dematel based approach. Computers and Industrial Engineering, 138, 106-118. https://doi.org/10.1016/j.cie.2019.106118

Rashid, S. (2013). The role of quick response for demand driven globalized apparel supply chain management. İçinde J. Xu, M. Yasinzai, \& B. Lev, (Ed.), Lecture Notes in Electrical Engineering (pp. 643-654). Springer-Verlag London.

Roth, A. (2016). Industrie 4.0 - hype oder revolution? in: einführung und umsetzung von industrie 4.0, $1-15$.

Rüßmann, M., M. Lorenz, P. Gerbert, M. Waldner, J. Justus, P. Engel \& M. Harnisch. (2015). Industry 4.0: The future of productivity and growth in manufacturing industries. Boston Consulting Group, 9(1): 54-89.

Saunders, M., P. Lewis, and A. Thornhill (2009). Research methods for business students. fifth edition. Harlow: Pearson Education Limited.

Sentryo. (2019). Industrial revolutions: the 4 main revolutions in the industrial world. https://www.sentryo.net/the-4-industrial-revolutions/

Siepmann, D. (2016). Industrie 4.0 - Fünf zentrale Paradigmen. In: Einführung und umsetzung von Industrie 4.0, 35-46.

Stearns, P. N. (2012). The Industrial Revolution in World History (4th ed.). Routledge.

Stoltz, M.H., Giannikas, A., McFarlane, D., Strachan, J., Um, J., \& Srinivasan, R. (2017). Augmented reality in warehouse operations: opportunities and barriers. IFAC PapersOnLine, Volume 50(1), 12979-12984.

Strandhagen, J. O., Vallandingham, L. R., Fragapane, G., Strandhagen, J. W., Stangeland, A. B. H., \& Sharma, N. (2017). Logistics 4.0 and emerging sustainable business models. Advances in Manufacturing, 5(4), 359-369.

Sun, J. (2012). Design and implementation of IOT-based logistics management system. Proceedings IEEE Symposium on Electrical and Electronics Engineering, 603-606.

Szymańska, O., Adamczak, M., \& Cyplik, P. (2017). Logistics 4.0-a new paradigm or set of known solutions?. Research in Logistics \& Production, 7, 299-210. https://doi.org/10.21008/j.20834950.2017.7.4.2

Timm I. J., Lorig F. (2015). Logistics 4.0 - A challenge for simulation. 2015 Winter Simulation Conference (WSC). 3118-3119. https://doi.org/10.1109/WSC.2015.7408428

Tiwari, S.T.S., Chan, S.W., Ahmad, M.F., \& Zaman, I. (2019). Application and implementation of eprocurement technologies in malaysian manufacturing firm. International Journal of Supply Chain Management, 8(2), 923-929.

Voege, T. (2019), The future of transport services Discussion Paper, (No. IDB-DP-680). Transport Division, Interamerican Development Bank https://publications.iadb.org/publications/english/document/The Future of Transportation Ser vices_in_Latin_American_and_Caribbean_Countries_en_en.pdf 
Vries, P. 2008. The industrial revolution. Encyclopaedia of the Modern World, 4: 158-161.

Wang, G., Gunasekaran, A., Ngai, E. W., \& Papadopoulos, T. (2016). Big data analytics in logistics and supply chain management: Certain investigations for research and applications. International Journal of Production Economics, 176, 98-110. https://doi.org/10.1016/j.ijpe.2016.03.014

Wohlfeld, D. (2019). Digitaler Zwilling für die Produktion von Übermorgen. Zeitschrift Für Wirtschaftlichen Fabrikbetrieb, 114(1-2), 65-67. https://doi.org/10.3139/104.112008

Xu, Z., He, J., \& Chen, Z. (2012). Design and actualization of iot-based intelligent logistics system. In: IEEE International Conference on Industrial Engineering and Engineering Management, 22452248 .

Zhong, R.Y., Huanga, G.Q., Lana, S., Dai, Q.Y., Xu, C., \& Zhang, T. (2015). A big data approach for logistics trajectory discovery from RFID-enabled production data. International Journal of Production Economics, 165, 260-272. 


\section{EXTENDED ABSTRACT}

\section{Introduction}

Throughout history, technological breakthroughs have altered industries and its subsystems. The industrial revolution is the broad term for these impacts. Mechanical Revolution (Industry 1.0), Electrical Revolution (Industry 2.0) and Electronic/Automation Revolution (Industry 3.0) then started the Cyber/Physical Revolution (Industry 4.0) effect today. The notion of Industry 4.0 encompasses all efforts to enhance conventional production processes that cannot be abandoned, as well as information technologyenabled practices; it is critical for businesses to swiftly adapt to the interconnected world and industrial production. A smart transformation is taking place in all sectors on a global scale with Industry 4.0, which envisions a future of connected production in which interconnected machines and business processes communicate better with one another in order to optimize production and enable more efficient and sustainable individualized and mass production. In particular, the emergence of Industry 4.0 necessitated considerable changes in the logistics industry. Technological changes such as the visibility of the supply chain and integrated control systems are at the forefront of these. It has become a necessity for the logistics industry to adapt to this changing environment, with the increasing demand for individualized products and services.

\section{Materials and Methods}

Today, Industry 4.0 is still an evolving and highly diverse field of research. The application of exploratory research methods is an appropriate field. An integrative literature review was conducted to create a comprehensive perspective to define the relationship between logistics and industry 4.0. Based on the topic and current research in this field, a systematic review of Industry 4.0 in logistics and supply chain management was applied.

\section{Findings}

It took around two centuries for the three industrial revolutions to develop. The first industrial revolution, which began in the late 18th century with the use of water and steam-powered mechanical production facilities, is regarded one of humanity's most significant achievements. The introduction of electrically-powered mass production technology, through the division of labor, was later dubbed the second industrial revolution around the turn of the twentieth century. The third industrial revolution began in the mid-1970s, with the popularization of electronics and information technology in factories, to promote increased factory automation. The Fourth Industrial Revolution emerged through Cyber-Physical Systems. These systems are industrial automation systems that connect physical operations through their computer and communication infrastructures and networks and their accessibility to the cyber world. The concept of Industry 4.0, which is the last revolution, emerged for the first time at the Hannover Fair held in Germany in 2011 and is defined as the fourth stage of industrial revolutions and includes the increasing interconnection of products/systems. Industry 4.0 is defined as the networking of all human and machine actors and the digitization and real-time evaluation of all relevant information in order to optimize customer use throughout the value chain and make value creation processes more transparent and efficient to use smart products and services. Logistics activities have undergone various changes over time due to the constant change in consumer needs and expectations, globalization, the spread of technology-based communication and the diversification of activities to be carried out, and the impact of intense technological innovations in recent years. Considering the chronological development of industrial revolutions, logistics processes have also been affected in parallel with each revolution in the production industry. The logistics sector affected by Industry 4.0, Logistics 4.0, is defined as smart logistics in most studies and is an important approach for a more efficient organization in terms of logistics and information logistics. Material flow throughout the product lifecycle and between product lifecycles will be handled by intelligent logistics. Smart logistics allows smart services to be included in logistics as well as smart products. Technical developments such as smart logistics or logistics 4.0 partially create the necessary conditions for the implementation of concrete solutions for new business models. 


\section{Discussion}

Logistics 4.0 is based on the cooperation of all technological foundations in order to ensure the change brought about by global competition and changing customer demands. For this reason, digitalization is a process that must be carried out carefully. Disruptive technologies such as additive manufacturing/3D printing, augmented reality, big data analytics, blockchain technology, cloud services, collaborative planning forecasting and replenishment, drones, electronic data interchange, e-procurement, enterprise resource planning, global positioning systems and general packet radio services (GPS and GPRS), pick-to-light and pick-by-voice, radio frequency identification, sales and operations planning, internet of things, transportation management system, warehouse management system, wearable technologies and digital twin have begun to integrate high connectivity and mobile technology capabilities and are referred to as Industry 4.0, which represents a new approach and technology research trend for logistics. Technology is not an end in itself, but a means to meet current development demands with intergenerational equity and to improve the competitiveness and sustainability of needed logistics operations. Our environment is shaped by three phenomena called space, people and time. Previously, it was eliminated through mass production due to time constraints. Industry 4.0 foresees the destruction of space from these phenomena and it happens very quickly. It took 4,300 thousand years to complete Industry 1.0, 70 years to move from Industry 2.0 to 3.0 , and 45 years to transition from Industry 3.0 to 4.0. For this reason, in order to be a part of the rapidly progressing digitalization rather than keeping up, it is necessary to be the implementer of the technologies that form the basis of Logistics 4.0. When we approach change from this perspective, the value chains formed within the framework of Industry 4.0, from raw material supply to production line, from production line to consumption points, will naturally trigger the transformation in the logistics sector. Applications that will strengthen the integration into the value chain according to the needs of Industry 4.0 are among the most important issues that will come to the agenda in the coming period. 